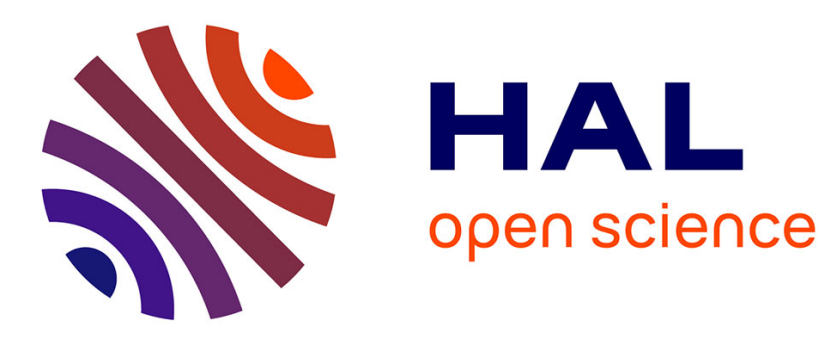

\title{
Beneficial vascular risk profile is associated with amyotrophic lateral sclerosis
}

Nadia Sutedja, Yvonne van Der Schouw, Kathelijn Fischer, Eefje Sizoo, Mark Huisman, Jan Veldink, Leonard van den Berg

\section{- To cite this version:}

Nadia Sutedja, Yvonne van Der Schouw, Kathelijn Fischer, Eefje Sizoo, Mark Huisman, et al.. Beneficial vascular risk profile is associated with amyotrophic lateral sclerosis. Journal of Neurology, Neurosurgery and Psychiatry, 2011, 82 (6), pp.638. 10.1136/jnnp.2010.236752 . hal-00629465

\section{HAL Id: hal-00629465 \\ https://hal.science/hal-00629465}

Submitted on 6 Oct 2011

HAL is a multi-disciplinary open access archive for the deposit and dissemination of scientific research documents, whether they are published or not. The documents may come from teaching and research institutions in France or abroad, or from public or private research centers.
L'archive ouverte pluridisciplinaire HAL, est destinée au dépôt et à la diffusion de documents scientifiques de niveau recherche, publiés ou non, émanant des établissements d'enseignement et de recherche français ou étrangers, des laboratoires publics ou privés. 


\section{Beneficial vascular risk profile is associated with amyotrophic lateral sclerosis}

N.A. Sutedja, MD; Y. T. van der Schouw, MD, PhD; K. Fischer, MD, PhD;

E.M. Sizoo, MD; M.H.B. Huisman, MD; J. H. Veldink*, MD, PhD

and L.H. Van den Berg*, MD, PhD

* These authors contributed equally

From the Departments of Neurology, Rudolf Magnus Institute of Neuroscience (Drs. Sutedja, Sizoo, Huisman, Veldink, and Van den Berg) and Julius Centre for Health Sciences and Primary Care (Drs. Van der Schouw and Fischer), University Medical Centre Utrecht, Utrecht, The Netherlands.

Leonard H. van den Berg, MD, PhD, Department of Neurology, G03.228

University Medical Centre Utrecht, P.O. Box 85500

3508 GA Utrecht, The Netherlands

Tel: +31-88-7557939, Fax: +31-30-2542100, E-mail: $\underline{\text { berg@umcutrecht.nl }}$

Supported by the VSB fonds, The Brain Foundation of the Netherlands, Prinses Beatrix Fonds (PBF) and the Catharijne Stichting. We would like to thank H. Kersten and M. Kersten for their generous support as well as J.R. van Dijk and the Adessium foundation.

The authors report no conflict of interest.

Running head: Vascular Profile and ALS Risk

Character count: title 89, running head 29

Word Count: abstract 248, body 2472; Number of tables: 5 


\begin{abstract}
Objectives

Reports of increased amyotrophic lateral sclerosis (ALS) with hyperlipidemia and elevated plasma homocysteine levels as well as cigarette-smoking and polymorphisms in angiogenic genes suggest a role for altered vascular homeostasis in ALS pathogenesis. We assessed the association between vascular risk factors and ALS.
\end{abstract}

\title{
Methods
}

Traditional cardiovascular risk factors (smoking, hypertension, hypercholesterolemia, diabetes and body mass index (BMI)) and cardiovascular disease prior to ALS onset established by a questionnaire were compared in 334 patients and 538 age- and sex-matched controls. Biochemical assessments (total cholesterol (TC), low-density lipoprotein (LDL), high-density lipoprotein (HDL), hs-CRP, and homocysteine) at diagnosis were measured in blood samples of 303 patients with ALS and compared with prospectively collected data from 2100 population-based controls.

\section{Results}

Patients with ALS used cholesterol-lowering agents less frequently (OR=0.6, p=0.008), had a lower BMI $(\mathrm{OR}=0.9, \mathrm{p}=0.001)$, a lower $\mathrm{LDL} / \mathrm{HDL}$ ratio (women: $\mathrm{OR}=0.5, \mathrm{p}<0.001$; men: $\mathrm{OR}=0.4, \mathrm{p}<0.001$ ) and lower homocysteine levels (women: $\mathrm{OR}=0.9, \mathrm{p}=0.02$; men: $\mathrm{OR}=0.9$, $\mathrm{p}<0.001)$. Mean LDL and TC levels were significantly lower among patients with a lower functional vital capacity percent of predicted (FVC). In the univariate analysis, a higher LDL/HDL ratio correlated with increased survival $(\mathrm{HR}=0.9, \mathrm{p}=0.04)$; after adjusting for the confounders age, site and FVC, no difference was observed. 


\section{Conclusions}

Vascular risk factors, measured clinically and biochemically, were not associated with increased ALS. Instead patients reported less use of cholesterol-lowering medication, had a lower premorbid BMI and favourable lipid profile - all findings consistent with the hypothesis that higher metabolic rate plays a role in ALS. 


\section{INTRODUCTION}

Studies on angiogenic factors have suggested a role for altered vascular homeostasis in amyotrophic lateral sclerosis (ALS) pathogenesis. In several human populations, VEGF haplotypes associated with low vascular endothelial growth factor (VEGF) levels are more prevalent among ALS patients, and mice expressing reduced VEGF levels develop motor neuron degeneration. ${ }^{1-3}$ Moreover, the functionally similar angiogenin has been associated with ALS. ${ }^{4-6}$ Vasculature damage may be an early pathological event leading to motor neuron degeneration in the transgenic mutated SOD1 mouse model of ALS. ${ }^{7}$

Findings have suggested vascular risk factors to contribute to neurodegeneration in Alzheimer's disease. ${ }^{8-11}$ Only one study examined the presence of multiple vascular risk factors in ALS patients, ${ }^{12}$ but remained inconclusive due to a small study size. Other studies have focused on blood levels of specific vascular parameters: reports of higher plasma homocysteine ${ }^{13}$ and higher lipid ${ }^{14}$ levels seem to suggest atherogenic risk factors in ALS; however, the lack of association between lipid levels and ALS in a more recent study was not able to reinforce this hypothesis. ${ }^{15}$ Moreover, the implication of the protective effect of higher lipid levels on disease progression found in one study, ${ }^{14}$ but not in another study, ${ }^{15}$ requires further elucidation. These different results have been suggested to be partly explained by an association of lower lipid status with lower respiratory function. ${ }^{15}$

The aim of the present study was to assess the hypothesis that a higher risk profile for vascular disease, measured by clinical and biochemical indicators, was associated with susceptibility for developing ALS and to assess the association with survival in patients, after adjusting for confounders. 


\section{METHODS}

\section{Patients}

Between July 1, 2004 and July 1, 2009, patients diagnosed with sporadic ALS at the University Medical Centre Utrecht, a tertiary referral clinic in The Netherlands, were recruited. Diagnosis was made according to the El Escorial Criteria after exclusion of other conditions. Patients diagnosed with possible, probable or definite ALS according to the El Escorial criteria were included. Age and site of onset of disease were recorded. Onset of disease was defined as the time of initial weakness, dysarthria or dysphagia. The study protocol was approved by the institutional ethical committee of the University Medical Centre Utrecht.

\section{Questionnaire study}

In the questionnaire study, 334 patients and 538 controls were included. Controls were derived from two sources. Each case was asked to approach an individual meeting the following criteria: 1) not a spouse, partner, or blood relative, 2) age difference of 5 years or less, 3) same sex. Also, the general practitioner of the patient was asked to select a control randomly from his clinic meeting the same criteria.

Demographic characteristics (age, sex, level of education), and occurrence of traditional vascular risk factors and disease were ascertained by a questionnaire. Hypertension, hypercholesterolemia, and diabetes were classified as present when use of disease-specific medication was reported. Data on cigarette-smoking habits, height and weight during adulthood were collected. Body mass index (BMI) was calculated and overweight was defined as BMI $\geq 25 \mathrm{~kg} / \mathrm{m}^{2}$. In patients with ALS, only data referring to the period before onset of first symptoms were analyzed. Occurrence of vascular disease was ascertained by questions relating to ever having had a myocardial infarction (MI), angina pectoris (AP), 
stroke and transient ischemic attacks (TIA), or peripheral bypass or angioplasty (peripheral vascular disease (PVD)).

\section{Blood sample study}

In the blood sample study, 303 patients and 2100 controls were included. There is overlap between the two patient cohorts from the questionnaire and blood sample studies. Both cohorts are derived from the same source patient population (tertiary referral centre). In both cohorts patients were sampled for inclusion. Controls were recruited from participants enrolled in two prospective studies in The Netherlands described elsewhere. ${ }^{16-18}$ The HAMLET study was a single-centre, population-based cohort study in 400 men, aged 40 to 80 years, who lived independently. It was designed to explore vascular risk factors. ${ }^{16,17}$ Volunteers were recruited by means of invitation letters to a random sample of the municipal register of Utrecht and a database of potential volunteers nominated by volunteers of previous studies. The PROSPECT-EPIC study was a population-based cohort study of 17357 healthy women aged 50-70 recruited from breast cancer screening participants designed to assess the relation between nutrition and cancer. ${ }^{18}$ From this EPIC-cohort, 1700 women were randomly sampled for blood analysis.

Total cholesterol (TC), low-density lipoprotein (LDL), high-density lipoprotein (HDL), and its derived total LDL/HDL ratio, high sensitive (hs)-CRP, and homocysteine, have been shown to be independently associated with other vascular risk factors and disease. Nonfasting blood samples from patients with ALS at time of diagnosis, non-fasting blood samples from PROSPECT-controls and fasting blood samples from HAMLET-controls were collected. TC, LDL, HDL, glucose, hs-CRP were measured in all participants of PROSPECT $(\mathrm{n}=1700)$ and HAMLET $(\mathrm{n}=400)$. Homocysteine was measured in all $(\mathrm{n}=400)$ HAMLET and in a subset of the PROSPECT subjects $(n=950)$. TC, LDL, HDL, and homocysteine in 
plasma were measured using an enzymatic assay. ${ }^{19} \mathrm{Hs}-\mathrm{CRP}$ was measured in serum in patients and HAMLET control subjects. We adjusted for the plasma measurements of hs-CRP in the PROSPECT study by multiplying all values by 1.13 . Details of the measurements are provided elsewhere. ${ }^{17,19-21}$

Functional vital capacity percent of predicted (FVC) was measured in all patients at time of blood sampling.

\section{Statistical analysis}

We compared the prevalence of measures of cardiovascular risk in the ALS group to that of the control group. To determine whether ALS was associated with self-reported cardiovascular risk factors and events, logistic regression analysis was performed. In order to determine the increase in ALS risk with each unit of increment in serum values, logistic regression analysis adjusting for age was performed for women and men separately, because age and sex distribution differed among patients and controls.

FVC is known to be associated with survival. To assess this possible confounder in the survival analysis, the association between FVC and lipid levels was tested by linear regression. To determine whether survival was associated with self-reported cardiovascular risk factors and events, and blood levels of vascular risk factors, a univariate Cox regression and a multivariate Cox regression were performed, adjusting for age, site at onset and FVC at time of blood sampling, confounders significantly associated with survival. To determine whether serum values were influenced by duration of disease in patients with ALS, linear regression was used to study the association between blood levels and onset-diagnosis interval. A two-sided p-value $<0.05$ was considered significant. The study protocol was approved by the institutional ethical committee of the University Medical Centre Utrecht. All patients gave informed consent prior to the study. 


\section{RESULTS}

Participants

Table 1 shows the characteristics of 334 patients and 538 controls in the questionnaire study (table 1a) and 303 patients (131 women and 172 men) and 2100 controls (1700 women and 400 men) in the blood sample study (table 1b). In ALS patients, age and site at onset were similar to those reported in previous population-based studies. ${ }^{22}$ The response rate of the participants in the questionnaire study was $80 \%$. Characteristics of patients with ALS who completed questionnaires did not differ from those of patients with ALS for whom blood samples were available. Patient characteristics of participants and non-participants were similar. In the questionnaire study, sex and age were similar among patients and controls. In the blood sample study, patients were significantly older and there were more men than in the control population; therefore, we adjusted for these confounders.

\section{Vascular risk factors and $A L S$}

Table 2 shows the frequency of self-reported vascular risk factors in patients and controls. Compared to controls, fewer patients used cholesterol-lowering agents (OR=0.6, 95\% CI 0.4$0.9, \mathrm{p}=0.008)$ or were overweight $(\mathrm{OR}=0.7,95 \%$ CI $0.5-1.0, \mathrm{p}=0.02)$; moreover, patients had a lower BMI $(\mathrm{OR}=0.9,95 \%$ CI $0.9-1.0, \mathrm{p}=0.001)$.

Table 3 shows the blood levels of biochemical indicators of vascular risk in patients and controls. All lipid values were consistent with lower vascular risk in patients: TC and LDL were significantly lower, and HDL was significantly higher. LDL/HDL ratio was significantly lower in patients with ALS (in women, OR=0.4, 95\% CI 0.3-0.6, $\mathrm{p}<0.001$; in men, $\mathrm{OR}=0.5$, 95\% CI 0.4-0.6, $\mathrm{p}<0.001)$. The lipid profile in patients who completed the questionnaire did not significantly differ from those who did not complete questionnaires. 
Significantly lower homocysteine levels were found in patients with ALS (in women:

$\mathrm{OR}=0.9,95 \% \mathrm{CI} 0.9-1.0, \mathrm{p}=0.02$; in men: $\mathrm{OR}=0.9,95 \% \mathrm{CI} 0.8-0.9, \mathrm{p}<0.001)$. No significant associations between hs-CRP levels and ALS-status were observed. Stratification for disease duration did not show differences in measured blood levels (data not shown).

\section{Cholesterol levels and survival in ALS}

FVC and site at onset are known to be associated with survival. In patients with ALS, mean FVC was $87 \%$. Table 4 shows the lipid status according to respiratory function at the time of blood sampling. Mean LDL- and TC levels were significantly lower among patients with a lower FVC. Endpoints (i.e. death) were reached in 207 out of 331 patients with ALS in the questionnaire study. Median survival was 3.5 years. In the blood sample study, endpoints were reached in 101 of 131 female patients with ALS and 124 of 172 male patients. Median survival was 2.6 years (in women as well as in men). Univariate Cox regression showed a significantly increased survival for patients with a high LDL/HDL ratio in the male $(H R=0.8$, $\mathrm{p}=0.01)$ and total group $(\mathrm{HR}=0.9, \mathrm{p}=0.04)$ (table 5). This association disappeared in the multivariate Cox regression, after adjusting for age, site at onset and FVC (table 5). 


\section{DISCUSSION}

The results of our clinical and biochemical studies were all consistent with a more favourable vascular risk profile in patients with ALS than in controls; besides having lower homocysteine levels, ALS patients used cholesterol-lowering agents less frequently, had a lower premorbid BMI and obesity rate, and had a more favourable lipid profile. The finding of shorter survival for ALS patients with low lipid levels is in agreement with one previous study ${ }^{14}$, and suggests that a more favourable lipid profile is a risk factor as well as a disease modifying factor in ALS. However, we also observed a significant association between low FVC and lower lipid levels, suggesting an increased energetic demand or inflammatory status due to the increased respiratory effort. ${ }^{15}$ The significantly shorter survival of patients with a favourable lipid profile was no longer observed after adjusting for FVC indicating the effect of lipid levels on survival may be explained by this confounder. This may represent a state of debilitation in which poor FVC correlates with advanced disease and therefore poor nutrition. However, a causal effect of lipid levels on survival mediated by FVC cannot be excluded.

Only one previous study including 45 patients with ALS and 90 controls examined the presence of multiple vascular risk factors in ALS patients but was underpowered to detect an association between ALS and risk factors identified by chart review. ${ }^{12}$ The favourable lipid profile in patients with ALS in our study is in contrast to the reported higher ${ }^{14}$ or similar $^{15}$ blood cholesterol levels observed in patients with ALS in previous studies. These apparent discrepancies may have been caused by differences in the control population. In one study, ${ }^{14}$ lipid levels in controls were lower than in our study, which could be explained by an underrepresentation of persons with high cholesterol levels in the control population due to selection of health-conscious individuals as they used as controls visitors for routine cholesterol work-up in the hospital after excluding those with disorders associated with vascular disease. In a more recent study, ${ }^{15}$ the lipid levels in the controls were lower than in 
our study but controls taking lipid lowering drugs and those with diabetes mellitus were excluded which may have resulted in an underrepresentation of persons with high vascular risk and high cholesterol levels. ${ }^{15}$

Consistent with an earlier report, ${ }^{23}$ our study showed an increased incidence of ALS among premorbid, leaner individuals, which has been linked to an increased metabolic rate in patients with ALS and in mouse models prior to disease onset. ${ }^{24-26}$ Resting energy expenditure is increased in patients with ALS. Also, lower premorbid BMI has been previously found to be associated with ALS suggested to be a proxy for increased premorbid physical activity. ${ }^{23}$ These results therefore indicate that lipid profiles in ALS are a reflection of either increased premorbid physical activity or hypermetabolism. A recent review concludes that clinical and experimental studies have shown that abnormal energy homoeostasis has a role in ALS and altered lipid levels have been put forward as an explanation for energy imbalance in ALS. ${ }^{27}$ Another previously studied biochemical indicator associated with vascular disease is homocysteine, which has atherogenic and pro-thrombotic properties. ${ }^{28}$ Our study in 303 patients and 1350 controls showed lower homocysteine levels among patients, in contrast to the increased fasting homocysteine levels in 62 patients with ALS compared to 88 controls in a previous study. ${ }^{13}$ Homocysteine levels may be influenced by vitamin B6 and B12 levels. However, as vitamin B deficiencies lead to hyperhomocysteinemia, the corrected homocysteine levels in our patients would be even lower if they had vitamin B6 or B12 deficiencies. This factor does not, therefore, interfere with our conclusion that homocysteine levels in our patients are lower than in controls and discrepancies between studies are most probably attributable to differences in controls populations (outpatients in a tertiary clinic versus a prospective cohort in our study).

A consideration is that data for patients and controls in the blood sample study were ascertained in different ways. Non-fasting blood samples were collected from patients with 
ALS and from female controls, but fasting blood samples from male controls. This does not, however, explain the observed difference in levels of cholesterol and homocysteine between patients and controls; if results were influenced, we would expect an even larger difference in blood levels between patients and controls. Moreover, blood samples of patients were collected after onset of disease making a distinction between cause and consequence difficult. It would be interesting to go back in the patient records, well before the onset of ALS, to determine if the lipid markers were always in the favourable range. All blood samples were, however, collected at the first visit - usually a relatively early stage of the disease - and stratification for disease duration did not show differences between samples taken at an early stage and at a late stage. Also lipid controls were not age-matched, but we adjusted for this in our analyses.

In the questionnaire study we took into account onset of first weakness and only scored selfreported risk factors which occurred prior to disease onset. The finding of lower cholesterol levels in patients at diagnosis seem to agree with the data from self-reports of more frequent use of cholesterol-lowering agents and the low BMI preceding disease onset.

In the questionnaire study, a limitation is possible recall bias in the patient group. However, there was no indication of overreporting vascular risk factors in the patient group. Also, using acquaintances as controls could have contributed to overmatching which would bias the risk estimate towards the null. If the results were influenced, we would expect an even stronger association between ALS and use of cholesterol lowering medication. Moreover, the prevalence of vascular risk factors in our control group did not show major differences compared to the figures reported for the Dutch population in the national registry. This suggests that the control group (which also consisted of population-based individuals randomly selected by the general practitioner) is representative of the general population. 
The present study does not show cardiovascular risk factors and disease to be associated with ALS, but the association of ALS with a favourable lipid profile may support the hypothesis that an increased metabolism, as part of a complex genetic profile, independent of activity levels or diet, may play a role in the pathogenesis of ALS. Determining causation, however, requires more research.

\section{LICENCE FOR PUBLICATION}

The Corresponding Author has the right to grant on behalf of all authors and does grant on behalf of all authors, an exclusive licence (or non exclusive for government employees) on a worldwide basis to the BMJ Publishing Group Ltd to permit this article (if accepted) to be published in JNNP and any other BMJPGL products and sublicences such use and exploit all subsidiary rights, as set out in our licence. (http://group.bmj.com/products/journals/instructionsfor-authors/licence-forms) 


\section{REFERENCES}

1. Lambrechts D, Storkebaum E, Morimoto M, et al. VEGF is a modifier of amyotrophic lateral sclerosis in mice and humans and protects motoneurons against ischemic death. Nat Genet 2003;34:383-94.

2. Van Vught PW, Sutedja NA, Veldink JH, et al. Lack of association between VEGF polymorphisms and ALS in a Dutch population. Neurology 2005;65:1643-5.

3. Oosthuyse B, Moons L, Storkebaum E, et al. Deletion of the hypoxia-response element in the vascular endothelial growth factor promoter causes motor neuron degeneration. Nat Genet 2001;28:131-8.

4. Greenway MJ, Andersen PM, Russ C, et al. ANG mutations segregate with familial and 'sporadic' amyotrophic lateral sclerosis. Nat Genet 2006;38:411-3.

5. Cronin S, Greenway MJ, Ennis S, et al. Elevated serum angiogenin levels in ALS. Neurology 2006;67:1833-6.

6. Wu D, Yu W, Kishikawa H, et al. Angiogenin loss-of-function mutations in amyotrophic lateral sclerosis. Ann Neurol 2007;62:609-17.

7. Zhong Z, Deane R, Ali Z, et al. ALS-causing SOD1 mutants generate vascular changes prior to motor neuron degeneration. Nat Neurosci 2008;11:420-2.

8. Regan C, Katona C, Walker Z, Hooper J, Donovan J, Livingston G. Relationship of vascular risk to the progression of Alzheimer disease. Neurology 2006;67:1357-62.

9. Luchsinger JA, Reitz C, Honig LS, Tang MX, Shea S, Mayeux R. Aggregation of vascular risk factors and risk of incident Alzheimer disease. Neurology 2005;65:545-51. 
10. Honig LS, Kukull W, Mayeux R. Atherosclerosis and AD: analysis of data from the US National Alzheimer's Coordinating Center. Neurology 2005;64:494-500.

11. Helzner EP, Luchsinger JA, Scarmeas N, et al. Contribution of vascular risk factors to the progression in Alzheimer disease. Arch Neurol 2009;66:343-8.

12. Armon C, Kurland LT, O'Brien PC, Mulder DW. Antecedent medical diseases in patients with amyotrophic lateral sclerosis. A population-based case-controlled study in Rochester, Minn, 1925 through 1987. Arch Neurol 1991;48:283-6.

13. Zoccolella S, Simone IL, Lamberti P, et al. Elevated plasma homocysteine levels in patients with amyotrophic lateral sclerosis. Neurology 2008;70:222-5.

14. Dupuis L, Corcia P, Fergani A, et al. Dyslipidemia is a protective factor in amyotrophic lateral sclerosis. Neurology 2008;70:1004-1009.

15. Chio A, Calvo A, Ilardi A, et al. Lower serum lipid levels are related to respiratory impairment in patients with ALS. Neurology 2009;73:1681-5.

16. Muller M, Grobbee DE, Aleman A, Bots M, van der Schouw YT. Cardiovascular disease and cognitive performance in middle-aged and elderly men. Atherosclerosis 2007;190:143-9.

17. Aleman A, Muller M, de Haan EH, van der Schouw YT. Vascular risk factors and cognitive function in a sample of independently living men. Neurobiol Aging 2005; 26:485-90.

18. Boker LK, van Noord PA, van der Schouw YT, et al. Prospect-EPIC Utrecht: study design and characteristics of the cohort population. European Prospective Investigation into Cancer and Nutrition. Eur J Epidemiol 2001;17:1047-53. 
19. van der A D, Marx JJ, Grobbee DE, et al. Non-transferrin-bound iron and risk of coronary heart disease in postmenopausal women. Circulation 2006;113:1942-9.

20. Dalmeijer GW, Olthof MR, Verhoef P, Bots ML, van der Schouw YT. Prospective study on dietary intakes of folate, betaine, and choline and cardiovascular disease risk in women. Eur J Clin Nutr 2008;62:386-94.

21. Nakhai-Pour HR, Grobbee DE, Bots ML, Muller M, van der Schouw YT. C-reactive protein and aortic stiffness and wave reflection in middle-aged and elderly men from the community. J Hum Hypertens 2007;21:949-55.

22. Beghi E, Logroscino G, Chio A, et al. The epidemiology of ALS and the role of population-based registries. Biochim Biophys Acta 2006;1762:1150-7.

23. Scarmeas N, Shih T, Stern Y, Ottman R, Rowland LP. Premorbid weight, body mass, and varsity athletics in ALS. Neurology 2002;59:773-5.

24. Desport JC, Torny F, Lacoste M, Preux PM, Couratier P. Hypermetabolism in ALS: correlations with clinical and paraclinical parameters. Neurodegener Dis 2005;2:202-7.

25. Desport JC, Preux PM, Magy L, et al. Factors correlated with hypermetabolism in patients with amyotrophic lateral sclerosis. Am J Clin Nutr 2001;74:328-34.

26.Dupuis L, Oudart H, Rene F, Gonzalez de Aguilar JL, Loeffler JP. Evidence for defective energy homeostasis in amyotrophic lateral sclerosis: benefit of a high-energy diet in a transgenic mouse model. Proc Natl Acad Sci U S A 2004;101:11159-64.

27. Dupuis L, Pradat PF, Ludolph AC, Loeffler JP. Energy metabolism in amyotrophic lateral sclerosis. Lancet Neurol 2011;10:75-82. 
28. Eikelboom JW, Lonn E, Genest J, Jr., Hankey G, Yusuf S. Homocyst(e)ine and cardiovascular disease: a critical review of the epidemiologic evidence. Ann Intern Med 1999;131:363-75.

Table 1a Characteristics of patients and controls in the questionnaire study population

\begin{tabular}{lrlrl} 
& \multicolumn{2}{c}{ ALS } & \multicolumn{2}{c}{ Controls } \\
& \multicolumn{2}{c}{$(\mathbf{n}=\mathbf{3 3 4})$} & \multicolumn{2}{c}{$(\mathbf{n = 5 3 8})$} \\
Median age ${ }^{*}$, yr (range) & 60 & $(24-82)$ & 59 & $(29-89)$ \\
Female, $\mathrm{n}(\%)$ & 145 & $(43)$ & 246 & $(46)$ \\
Site at onset, $\mathrm{n}(\%)$ & & & & \\
$\quad$ Bulbar & 86 & $(27)$ & & \\
$\quad$ Spinal & & & & \\
$\quad$ Cervical & 114 & $(36)$ \\
$\quad$ Thoracal & 4 & $(1)$ \\
$\quad$ Lumbosacral & 102 & $(32)$ \\
Multiple regions & 13 & $(4)$
\end{tabular}

All patients fulfilled the El Escorial criteria for probable and definite ALS.

* Age at onset was used in the multivariate analysis

Table 1b Characteristics of patients and controls in the blood sample study population

\begin{tabular}{|c|c|c|c|c|c|c|}
\hline \multirow[b]{2}{*}{ Median age ${ }^{\star}$, yr (range) } & \multicolumn{2}{|c|}{$\begin{array}{l}\text { ALS } \\
(n=303)\end{array}$} & \multicolumn{2}{|c|}{$\begin{array}{l}\text { Female } \\
\text { controlst } \\
(n=1700)\end{array}$} & \multicolumn{2}{|c|}{$\begin{array}{l}\text { Male } \\
\text { controls } \neq \\
(n=400)\end{array}$} \\
\hline & 64 & $(24-85)$ & 57 & $(50-70)$ & 61 & $(40-80)$ \\
\hline Female, n (\%) & 131 & (43) & 1700 & $(100)$ & 0 & $(0)$ \\
\hline \multicolumn{7}{|l|}{ Site at onset, n (\%) } \\
\hline Bulbar & 90 & (30) & & & & \\
\hline \multicolumn{7}{|l|}{ Spinal } \\
\hline Cervical & 98 & (33) & & & & \\
\hline Thoracal & 7 & (2) & & & & \\
\hline Lumbosacral & 100 & (33) & & & & \\
\hline Multiple regions & 4 & (1) & & & & \\
\hline
\end{tabular}

All patients fulfilled the El Escorial criteria for probable and definite ALS.

* Age at diagnosis was used in the multivariate analysis

+ Female controls were derived from the PROSPECT study (Boker, 2001)

₹ Male controls were derived from the HAMLET study (Aleman, 2005; Muller, 2007) 
Table 2 Self-reported indicators of risk profile for cardiovascular diseases in patients and controls

\begin{tabular}{|c|c|c|c|c|c|c|}
\hline \multirow[b]{2}{*}{ Traditional risk factors } & \multicolumn{2}{|c|}{$\begin{array}{c}\text { ALS } \\
(n=334)\end{array}$} & \multicolumn{2}{|c|}{$\begin{array}{l}\text { Controls } \\
(n=538)\end{array}$} & ORt & $\mathbf{p}$ \\
\hline & & & & & & \\
\hline \multicolumn{7}{|l|}{ Smokers, n (\%) } \\
\hline Current & 56 & $(17)$ & 84 & $(16)$ & 1.0 & 0.9 \\
\hline Former & 138 & $(43)$ & 243 & $(46)$ & 0.9 & 0.4 \\
\hline Never & 129 & $(40)$ & 197 & $(38)$ & - & - \\
\hline Anti-hypertensive use, $\mathrm{n}(\%)$ & 81 & $(26)$ & 135 & $(26)$ & 1.0 & 1.0 \\
\hline Anti-diabetic use, $\mathrm{n}(\%)$ & 15 & (5) & 29 & $(6)$ & 0.8 & 0.6 \\
\hline Cholesterol lowering agents use, $n(\%)$ & 35 & (11) & 91 & $(17)$ & 0.6 & $0.008^{*}$ \\
\hline All risk factors & 105 & $(34)$ & 184 & $(36)$ & 0.9 & 0.5 \\
\hline \multicolumn{7}{|l|}{ Cardiovascular events } \\
\hline Myocardial infarction, n (\%) & 13 & $(4)$ & 21 & $(4)$ & 1.1 & 0.9 \\
\hline Angina pectoris, $\mathrm{n}(\%)$ & 12 & $(4)$ & 24 & $(5)$ & 0.8 & 0.6 \\
\hline Stroke or TIA, n (\%) & 9 & (3) & 17 & (3) & 0.9 & 0.7 \\
\hline Peripheral arterial disease, $\mathrm{n}(\%)$ & 5 & (2) & 8 & (2) & 1.0 & 1.0 \\
\hline All vascular events & 34 & (11) & 61 & $(12)$ & 1.0 & 0.9 \\
\hline \multicolumn{7}{|l|}{ Other } \\
\hline BMI, mean \pm SD & $25 \pm 3.5$ & & $26 \pm 3.6$ & & 0.9 & $0.001^{*}$ \\
\hline Obese, n (\%) & 140 & $(46)$ & 287 & $(55)$ & 0.7 & $0.02^{*}$ \\
\hline
\end{tabular}


Sutedja 19 
Table 3 Measurements in blood of vascular risk factors in patients and controls

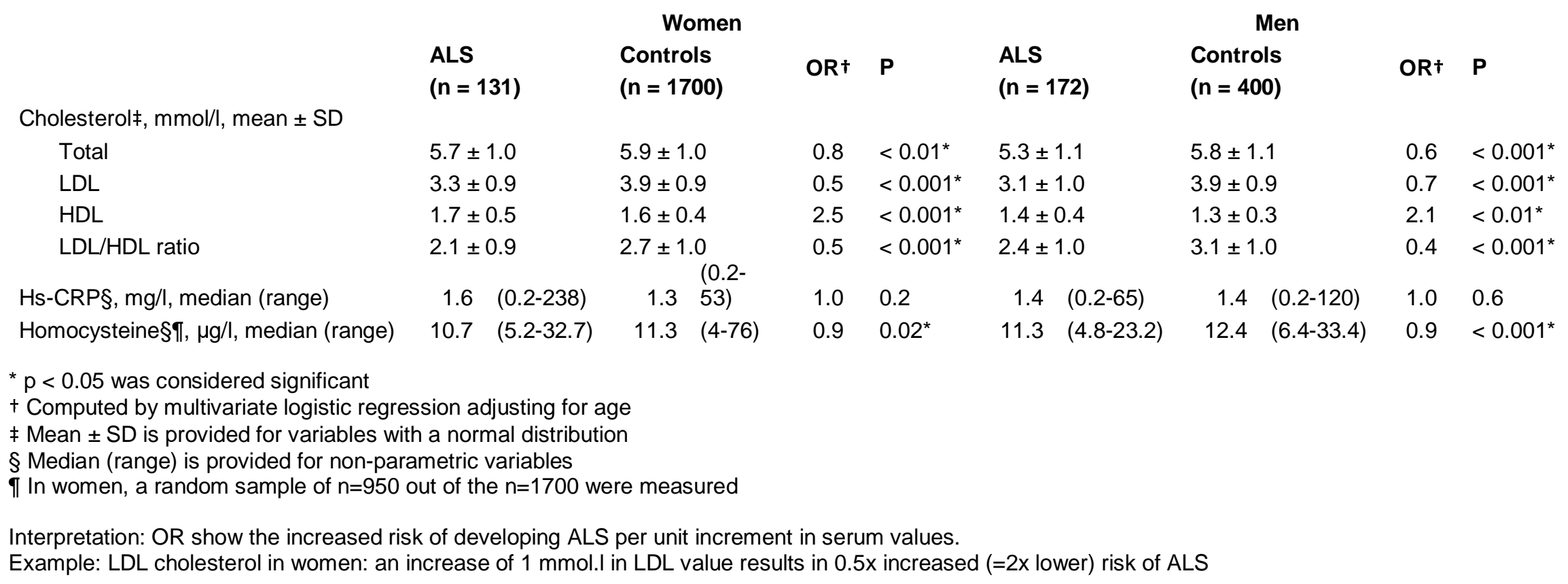


Table 4 Lipid status according to respiratory function at time of blood sampling

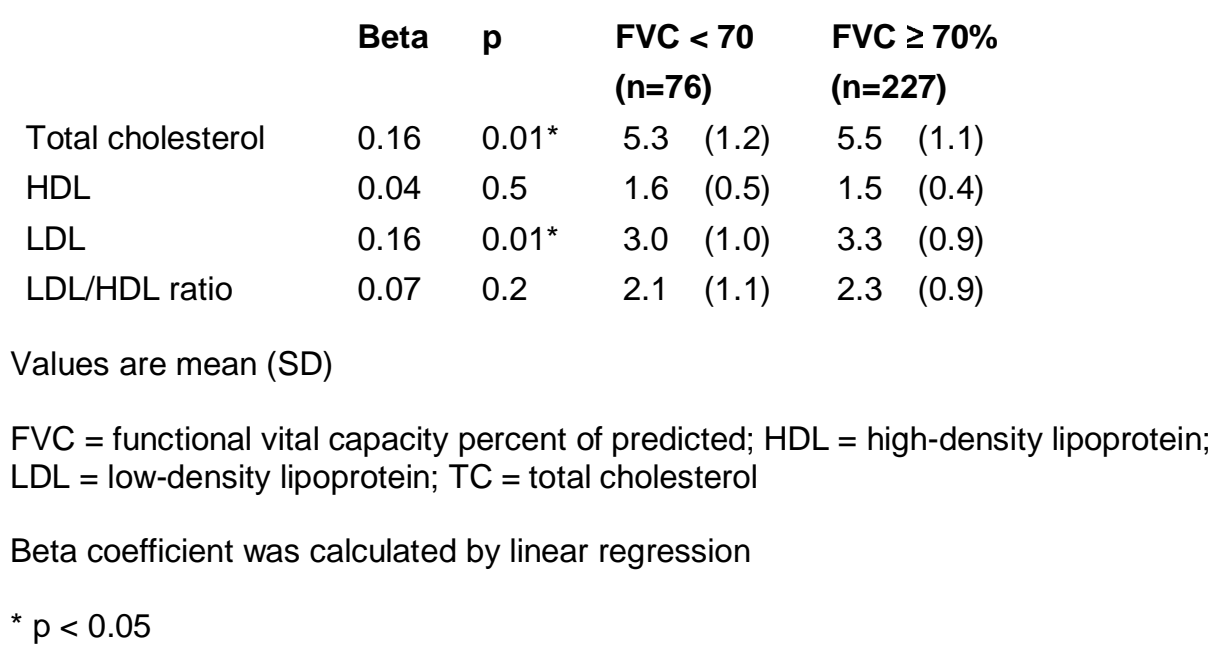


Table 5 Association between survival in ALS and LDL/HDL ratio

\begin{tabular}{|c|c|c|c|c|c|c|}
\hline & \multicolumn{2}{|c|}{ All } & \multicolumn{2}{|c|}{ Women } & \multicolumn{2}{|c|}{ Men } \\
\hline & HR & p & HR & $\mathbf{p}$ & HR & $\mathbf{p}$ \\
\hline Univariate regression & 0.9 & $0.04^{*}$ & 1.0 & 0.9 & 0.8 & $0.01^{*}$ \\
\hline Multivariate regressiont & 0.9 & 0.2 & 1.0 & 0.8 & 0.8 & 0.05 \\
\hline Multivariate regression‡ & 0.9 & 0.2 & 1.0 & 1.0 & 0.9 & 0.2 \\
\hline
\end{tabular}

